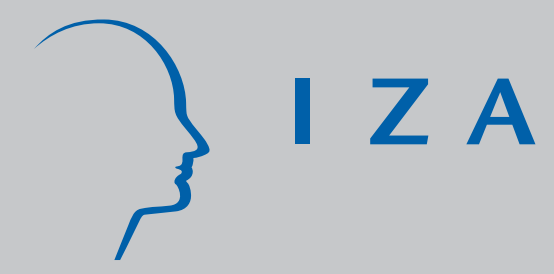

IZADP No. 1617

Parental Leave - A Policy Evaluation of the Swedish "Daddy-Month" Reform

J ohn Ekberg

Rickard Eriksson

Guido Friebel

May 2005 


\title{
Parental Leave - A Policy Evaluation of the Swedish "Daddy-Month" Reform
}

\author{
John Ekberg \\ SOFI, Stockholm University \\ Rickard Eriksson \\ SOFI, Stockholm University \\ Guido Friebel \\ University of Toulouse (EHESS and IDEI), \\ CEPR and IZA Bonn
}

Discussion Paper No. 1617

May 2005

\author{
IZA \\ P.O. Box 7240 \\ 53072 Bonn \\ Germany
}

Phone: +49-228-3894-0

Fax: +49-228-3894-180

Email: iza@iza.org

Any opinions expressed here are those of the author(s) and not those of the institute. Research disseminated by IZA may include views on policy, but the institute itself takes no institutional policy positions.

The Institute for the Study of Labor (IZA) in Bonn is a local and virtual international research center and a place of communication between science, politics and business. IZA is an independent nonprofit company supported by Deutsche Post World Net. The center is associated with the University of Bonn and offers a stimulating research environment through its research networks, research support, and visitors and doctoral programs. IZA engages in (i) original and internationally competitive research in all fields of labor economics, (ii) development of policy concepts, and (iii) dissemination of research results and concepts to the interested public.

IZA Discussion Papers often represent preliminary work and are circulated to encourage discussion. Citation of such a paper should account for its provisional character. A revised version may be available directly from the author. 


\section{ABSTRACT \\ Parental Leave - A Policy Evaluation of the Swedish "Daddy-Month" Reform*}

Many countries are trying to incentivize fathers to increase their share in parental leave and in household work to improve female labor market opportunities. Our unique data set stems from a natural experiment in Sweden. The data comprises all children born before (control group) and after the reform (treatment group) in cohorts of up to 27,000 newborns, mothers and fathers. We find strong short term effects of incentives on male parental leave. However, we find no learning-by doing, or specialization, effects: fathers in the treatment group do not have larger shares in the leave taken for care of sick children, which is our measure for household work.

JEL Classification: J48, J13, J16, J22

Keywords: natural experiment, family benefits, gender and labor, incentives

Corresponding author:

Guido Friebel

IDEI, Université de Toulouse 1

Manufacture des Tabacs

21 allée de Brienne

31000 Toulouse

France

Email: friebel@cict.fr

\footnotetext{
* Previous title: "Sharing Responsibility? Short- and Long-term Effects of Sweden's Daddy-Month Reform". We thank Anders Björklund, Antoine Bommier, Hielke Buddelmeyer, Oscar Nordström Skans, Mickael Salabasis, FredericWarzynski and seminar participants at FIEF, IFAU, IUI, National Social Insurance Board (RFV), Stockholm University, SOFI (all Stockholm), Gothenburg, Uppsala, Pompeu Fabra (Barcelona), Toulouse, Dept. of Trade and Industry (UK Government), Department of Family and Community Services (Australian Government), the Annual Conference of ESPE 2003 (New York), EEA Meeting 2004 (Madrid), SPEAC at ANU (Canberra). Financial support from RFV, Jan Wallander and Tom Hedelius Foundation, Swedish Council for Working Life and Social Research, and from SITE is gratefully acknowledged. All errors are ours.
} 


\section{Introduction}

Family benefit systems constitute an important element of the modern welfare state. The design of these systems differs considerably across countries, but paid leave is one of its cornerstones in most OECD countries. ${ }^{1}$ The Nordic countries have very generous paid leave systems, and for a long time, they have been concerned with designing paid leave in such a way as to increase gender equality. This explains why Norway and Sweden transformed their maternity leave systems into parental leave systems as early as in the 1970s, with a view of increasingly involving fathers in child care and household work.

Currently, a large number of countries are reconsidering their family benefit systems. They extend parental leave, an extension which then also entails gender restrictions. ${ }^{2}$ In Denmark, Italy and Norway, for instance, at least one month of the extension is a "use it or lose it" option for fathers. In Austria, two years of extended leave is offered, but only if the father takes at least six months of leave before the child turns three (Gatenio and Kamerman, 2002). Iceland has introduced the most radical reform. Here, three months are allocated to fathers, three to mothers. Only three months can be freely allocated between the parents. All these policies aim at providing fathers with stronger incentives to take parental leave, and share household work and the responsibility for child care. However, it is very difficult to provide estimates on the effects of these policies as data sets stemming from sufficiently controlled experiments are rare.

We investigate a reform of the parental leave system in Sweden which resulted in a clean natural experiment. The goal of the reform was to incentivize men to take more parental leave. It was expected that men would then learn more about their children, i.e. acquire more of the human capital needed for child care. This would make them take more responsibility for the family which would then, through a number of channels (described below), help dealing with unequal female labor market outcomes. Using registry data for the entire population of children born in cohorts before (control group) and after the reform (treatment group), we observe cohorts of up to 27,000 newborns, their fathers and mothers over a span of eight years. We find that short-term incentives work: men take much more parental leave after the reform. However, we find no evidence for learning-by-doing (human capital)

\footnotetext{
${ }^{1}$ Only Australia, South Korea and the US make no statutory provision for paid leave (see Bittman et al, 2004).

${ }^{2}$ For overviews of reform trends see Gornick and Meyers (2004), Bertelsmann Foundation (2003) and Ferrarini (2003). Ruhm (1998) and Ruhm and Teague (1997) provide comparisons of institutions for parental leave.
} 
effects: fathers in the treatment group do not have larger shares in the leave taken for care of sick children, which is our measure for household work.

In general, it is difficult to evaluate the effect of reforms in social benefit systems. However, our data are unique: they originate from the registry of the institutions paying the benefit, rather than being self-reported; furthermore, we are not studying a sample, but the entire population of children in a given period of time. Most importantly, the data stem from a clean natural experiment. The exact birth date of a child is the outcome of a random process and the parents' influence is only marginal. ${ }^{3}$ Thus, we avoid the potential problem of omitted variables, which would make it impossible to distinguish the effects of the reform from correlated influences. As the reform induces an exogenous increase in parental leave, any potentially observed long-run behavioral changes of parents in the treatment cohorts should be a result of the reform.

To provide some background to the reform: Next to Norway, Sweden was the first country undertaking reforms to give fathers stronger incentives to take parental leave. Swedish parental leave provides generous support. At the time of the reform, one year of parental leave at a replacement rate of $80 \%$ was available. In contrast to many other countries, fathers and mothers were both eligible for parental leave but, prior to the reform, women took the bulk of parental leave. On the first of January 1995, the government introduced the "Daddy-month" reform, reserving one month of the total parental leave available per child for the father.

The government believed that the reform would incite fathers to spend more time with their children in the first years of their lives. It expected the reform to increase fathers' shares in child care in the long run, contributing to long-run improvements in gender roles and more equal labor market outcomes:

"It is important that fathers take parental leave. An increased use of parental leave by fathers should contribute to a change in attitudes among managers; they will view parental leave as something natural to consider when planning and organizing the work. This change in attitudes is necessary for both men and women to dare to take parental leave without a feeling of jeopardizing their career or development opportunities at work. Another reason for increasing fathers' use of parental leave is that women's prospects of achieving equal opportunities to men in the labor market will

\footnotetext{
${ }^{3}$ We discuss further in Section 3.2 why we are confident that birth cannot be much influenced by parents.
} 
be limited, as long as women are responsible for practical housework and children. A shared responsibility for the practical care of children would mean a more even distribution of interruptions in work between women and men, and women would thereby gain better opportunities of development and making a career in their profession." From the Government Proposition 1993/94:147 to the Swedish Parliament, translation by the authors.

As shown by the quote, the government was not only concerned about how more male parental leave would help change gender roles and reduce the scope of discrimination. Rather, a number of economic forces were evoked. Prior to the reform, there was (statistical) discrimination against men taking parental leave (Albrecht et al, 1999, Stafford and Sundström, 1996). The government believed that this effect would be mitigated if more men were to take parental leave, because job disruptions owing to parental leave would be less concentrated to women. Furthermore, there was a strong belief in society and in the government that a more equal allocation of parental leave would lead to less specialization of female human capital into household and child care work. This rationale is related to Becker's theories of human capital and the family (Becker, 1965, 1981, and 1985 and Rosen, 1983), and was reflected in the work of Swedish economists engaged in the public debate (Henrekson, 1993). The following quote from an interview with a father is representative for the human-capital related view on parental leave:

"If you have been there from the beginning, you also want to be there later on. I took the first step when they [the children] were little. It is like planting a flower, it gets more exciting when it grows up. You want to be there all the time." From Nilsson (1994), translation by the authors.

The potential effects of the reform can be translated into two hypotheses that we test in this paper. First, as a result of the reform, fathers ought to increase their parental leave. Comparing the treatment and the control group, we indeed find that the reform substantially increases male parental leave. On average, male parental leave days increase by 15 days (around $50 \%$ ), an increase that can be decomposed into two main effects: a) fathers take more parental leave when their child is between one and two years old (arguably a time when links between fathers and children are important and much can be learnt about child care); b) for parental leave taken when the child is more than two years old, there is a very clear seasonal pattern with fathers taking more leave in the summer months and around Christmas (parental leave may hence simply be a prolongation of the regular paid holidays). 
The second hypothesis concerns the acquisition of human capital for household work. As pointed out by Becker, a parent who, today, specializes in household work (for instance, child care) will have a stronger future comparative advantage in household work. This leads to specialization of the two parents into household or "marketable" human capital. This specialization hypothesis is tested using a proxy of household work from data of a second benefit system, the leave for care for sick children. Comparing the treatment and control groups, we cannot find any support for the hypothesis that more male parental leave would translate into a higher share of male household work in the care for sick children. It appears that the purported link between parental leave and human capital investment in household work does not exist, or that the specialization theory is not a major cause for the uneven distribution of household work between men and women, or that the effect of the reform was too weak to have any significant effects. This issue is further discussed in Section 5 .

There may be many other potential effects that only materialize gradually. Changes in norms about male and female behavior, or changes in the organization of the workplace to accommodate more frequent parental leave by fathers do not occur instantaneously. These gradual changes may be important, and the reform might have an impact on these, but we cannot measured them. The reform would have a similar effect on before and after cohorts. Hence, we cannot look at these effects.

There is a substantial literature trying to estimate the effect of children, and family benefit systems on labor market outcomes of mothers, and conversely, the effect of labor market participation and family benefits on health and cognitive capacities of children. ${ }^{4}$ To the best of our knowledge, our paper is, however, the first attempt to measure the effect of changes in a family benefit system on behavior within households. This is very important as the degree to which the mother and father share child care and household work does not only affect the static labor supply of women, but also their acquisition of human capital for household work and work in the labor market. ${ }^{5}$ Furthermore, our data have the advantage that we need not consider labor

\footnotetext{
${ }^{4} \mathrm{~A}$ (far from exhaustive) list of interesting papers comprises Albrecht et al (1999), Bingly et al (1995), Browning (1992), Gregg et al (2005), Gruber (1994), Kunze and Ejrnaes (2005), Ruhm (1998), Schoenberg (2005) and Waldfogel (1998).

${ }^{5}$ The results of Ruhm (1998) who studies the effects of increased parental leave in a panel of nine European countries are in line with these considerations. He shows that the male-female wage gap increases in parental leave and argues that during parental leave, women do not invest in marketable human capital. Furthermore, he points to statistical discrimination against women who are expected to be away from work for a longer period of time when there is an increase in parental leave.
} 
market factors. Rather, we just look at the behavior of treatment vs. control groups of fathers in terms of participation in child care, i.e. our measure for household work.

The outline of the paper is as follows: The next section provides some background concerning the Swedish benefit systems for parental leave, the daddy-month reform and care for sick children. Section 3 describes the data and our empirical strategy. The effects of the reform are analyzed in Section 4. Section 5 discusses the implications of our study for the design of parental leave systems and Section 6 concludes.

\section{Background}

In most OECD countries, there is a tendency to increase family benefits. The OECD (2001) provides a summary indicator combining benefits such as the availability of child-care facilities, duration and replacement rates of maternity pay, and the possibility of voluntary leave from firms and flexibility of working hours. In this ranking, Sweden takes the top, followed by other Scandinavian countries and the Netherlands. It is also striking that the degree to which fathers participate in the system differs a great deal across countries, and that Sweden takes the top rank here as well (Gatenio and Mamerman, 2002).

While the bulk of benefits go to mothers, many countries now try to move away from traditional gender roles (Ferrarini, 2003). Hence, some family benefits are now designed in such a way as to increase the responsibility of fathers for child care, and improve the labor market opportunities of mothers. Sweden has been at the forefront of this tendency for at least three decades. As early as 1974, the Swedish maternity-leave system was changed to a parentalleave system, where the same rules apply to fathers and mothers. In the first year after the reform, men only used 0.5 percent of the total parental leave per household. By 1994, this figure had increased to 11.4 percent. The 1995 reform aimed at further increasing this percentage. Furthermore, from January 1, 2002 onwards, parents are entitled to 390 days of parental leave with two months reserved for each parent. This does not affect the parental leave for children born under the period studied, but it shows that the Swedish government plans to continue the path taken with the 1995 reform studied here. There are strong groups in Swedish politics and society pushing for much more drastic changes to provide stronger incentives for fathers (see the Economist, 2004). 


\subsection{Parental leave before and after the reform}

For a maximum of 360 days per household, parents receive compensation with a reimbursement rate of between 75 and 80 percent for the period studied. During the first two years after the reform, there was also a bonus of 10 percent for the first month of parental leave. The compensation is relative to prior gross earnings and takes into account potential wage increases in the parent's profession. There is a compensation ceiling that constitutes a binding constraint for 12 percent of the fathers ${ }^{6}$ and 4 percent of the mothers in the sample at the time of the daddy-month reform.

There is an additional compensation system that provides a flat rate of 60 SEK/day (approximately USD 8) for 90 days. Parents without earnings (for instance, unemployed) receive compensation at this level for a total of up to 450 days of parental leave. Finally, in a separate system, fathers are entitled to 10 days of benefits in connection with the birth, which can be used although the mother is on parental leave. These ten days must be used during the first 60 days after the birth of the child.

Parental leave must be used before the child turns eight or finishes first grade in school, but more than 90 percent of the leave are used during the first two years of the child's life. Only one parent can use parental leave at a time, but they can both work part time, and use parental leave part time as long as total parental leave does not exceed full time.

The main effect of the reform is that for children born on or after January 1,1995 , one month is reserved for each of the parents. As almost all mothers used at least one month of parental leave before the reform, the restriction on the division of parental leave is only binding for fathers. Hence, the month reserved became known as the "daddy month".

The only difference in compensation before and after the reform concerns a decrease in the reimbursement level from 90 to 80 percent. However, this change affected both control and treatment groups in the same way. ${ }^{7}$

\subsection{Care for sick children}

The second benefit system - which we will use to measure potential human capital specialization effects of an increase in father's parental leave - is leave

\footnotetext{
${ }^{6}$ We only observe fathers who receive some payment for parental leave, approx. $85 \%$ of all fathers. Hence, this figure may not be fully representative, if the fathers not using the benefit system are higher (or lower) income earners than those who do.

${ }^{7}$ Furthermore, from January 1, 2002 onwards, parents are entitled to 390 days of parental leave with two months reserved for each parent. This does not affect the parental leave for children born under the period studied.
} 
granted for the care for sick children (CSC) up to the age of twelve. The reimbursement is based on current earnings and the replacement rates vary between 75 and 80 percent for the period studied. Parents can benefit from this system up to 60 days a year. Once more, the same replacement rules apply for control and treatment cohorts.

On average, during any given year, about $50 \%$ of the children in our parental leave data base show up in the statistics for care for sick children. That is, either the father or the mother or both have received leave for taking care of their sick children. This number is highest for two-year old children (65\%), and gradually declines for older children (RFV, 2002).

\section{Data description and empirical strategy}

We construct two types of cohorts of parents. The "before" and "after" reform cohorts (we will also use the terms "control" and "treatment") are constructed from population data collected by the Swedish National Social Insurance Board (Riksförsäkringsverket). None of the data are self-reported. Rather, the data are assembled from records obtained from local insurance offices, and cover all parental leave and the care for sick children taken between the years 1993-2003. We have information on geographical location, the starting date of parental leave and the extent of days (in shares if not a full day), the amount of the parent's cash benefit, and gender and date of birth for both the child and the parent. To access information for a child or parent, at least one withdrawal of parental leave benefits must be observed between quarter four of 1994 and quarter two of 2003, otherwise this information will be censored. Table 1 presents the number of observations in each cohort.

[Table 1 about here.]

\subsection{Hypotheses}

The government built its reform on two hypotheses. First, changing fathers' incentives would involve an increase in male parental leave and second, this increase would induce behavioral, long-term changes.

In the pre-reform system, parents had the choice of letting the mother, or the father, or none of the parents use parental leave. After the reform, the option is restricted to letting the father or none of the parents take parental leave during the month reserved for the father. Prior to the reform, most of the parental leave was taken by mothers. The government expected that 
removing the option for mothers to take all parental leave and reserving 30 days for the exclusive use of fathers would incite fathers to increase their parental leave. Second, the government expected that if fathers took more parental leave, they would learn about child care, thereby making them more prone to share the responsibility for child care with the mothers. The care for sick children leave (CSC system) provides a useful measure of the division of household work. In particular, in less flexible jobs, the disruptions owing to leave for sick children may be quite important and employers may prefer male employees, because they expect them to take less leave for this purpose.

Note that these hypotheses are in line with the effects of a standard labor supply model where fathers and mothers invest in two types of human capital: a) human capital for work on the labor market and b) human capital for household work. Consider that the time a parent spends with his/her child results in human capital acquisition for household work. Then, a relative increase in male human capital for household work should reduce male labor supply and increase female labor supply. In terms of the specific measure we use, the male share of care for sick children leave should also increase. This potential effect hinges on the assumption that fathers and mothers to some extent share the household work, even prior to the reform. If this were not the case, and only mothers were to take care of sick children, that is, if households were in a corner solution, the reform might improve male human capital for household work, but not enough to move to an interior solution. However, as will become clear below, this is not the case in Sweden. Hence, any effects on male human capital for household work of the reform should be visible in a changing allocation of household work between fathers and mothers.

\subsection{A natural experiment}

By design, birth is a random event. The timing of conception cannot be completely controlled by the parents. The exact birth date of a child, given the date of conception, is the outcome of a random process. The duration of pregnancy is normally distributed with a mean of 40 weeks and a standard deviation of two weeks. While the birth of a child cannot be postponed, it can, in principle, be triggered. However, we are not very concerned about this possibility. In discussions with Swedish doctors and midwives, we were told that triggering birth (except for health reasons) is considered highly unethical and against professional standards. We have also compared the number of births around the turn of the reform year 1995 with all other years between 1993 and 2003, the period for which we have data. Nothing seems to indicate that 1994/95 differs from any other year. 
We compare the behavior of parents in the control and treatment cohorts by simply looking at the distributions of parental leave and care for sick children of the respective cohorts. We follow all cohorts for exactly eight years (=2922 days). Parental leave can be used until the child turns eight or finishes first grade, whence the cut-off point. We look at two types of cohorts: first, before and after cohorts in a span of two weeks around the first of January 1995; second before and after cohorts of a span of three months. The first type of cohorts has the advantage of containing few, if any, seasonal effects, but when looking at subgroups, for instance income or age, the sample is rather small. The second type of cohorts deals with this problem, at the expense of filtering in more seasonal effects, changes in norms or macro-economic conditions etc.

[Table 2 about here.]

To re-enforce our point that we are looking at a truly natural experiment, Table 2 presents descriptive statistics for the age of fathers and mothers. The table shows there to only be small differences in the age distribution between the samples, and a t-test assesses that there is no statistically significant difference in the mean age between the before and after reform parents. Note that important background variables such as level of education and income are positively correlated with the parents' age. A difference between the parents in the control and treatment cohorts in any of these variables would hence shows as a difference in age. This argument may not hold for fathers, as there are missing data on age for a substantial fraction of fathers, but we have age data for over 99 percent of the mothers. The age of the mother and the father is strongly correlated, so a sample selection problem for fathers on, for example, education would show up in an age difference also for the mother. We have also looked at the geographical distribution of births and find no systematic differences between the cohorts in this respect either. Hence, it seems very unlikely that there is a systematic difference in the characteristics of parents in the control and treatment cohorts.

Hence, here we have what Rosenzweig and Wolpin (2000) have called a 'natural' natural experiment. The most important advantage of such a natural experiment is to avoid problems with omitted variables. Fathers' parental leave and their care for sick children are likely to be correlated for a number of reasons. For example, fathers with a traditional view of gender roles, fathers working for management with traditional views, or fathers with jobs where absence causes substantial problems, will all be less likely to take both parental leave and leave for care of sick children. It would then be impossible to determine the causal effect of parental leave on care for sick 
children, unless all these effects can be controlled for. But, in our experiment, there are no omitted variables, as we have an exogenous change in fathers' parental leave that is due to the daddy-month reform.

\section{Effects of the reform}

In this section, we investigate the effects of the reform on fathers' use of parental leave and fathers' share of care for sick children.

\subsection{Parental leave}

In Table 3, we present a comparison of the means of parental leave days for the two cohorts. We report the data for two systems: the 360-day system where parents receive a compensation of $80 \%$ of earnings and the additional 90-days system that provides a low flat rate. Fathers increase their parental leave in the 360-day system by about 15 days. It makes sense that this increase is below the 30 days reserved for fathers by the daddy-month reform, as some fathers would have used more than that even in the absence of the reform and others use less than the earmarked 30 days. For the same reasons, it is also intuitive that the decrease in mothers' parental leave outweighs the increase in fathers' parental leave. The t-ratio shows that there is a statistically significant difference in the means of parental leave days between the treatment and control cohort. Note also that the results for the 360-days system are not sensitive to the cohort size chosen.

[Table 3 about here.]

It is interesting to note that there is an increase in mothers' use of the 90-day system. We interpret this as a substitution effect: some mothers use this (less generous) system when their access to the more generous 360-day system is reduced. The increase in fathers' use of the 90-day system is harder to explain. However, the effect vanishes if we look at the three-month cohort; total parental leave per child then decreased by five days on average.

Finally, as a robustness check, we have experimented with many other cohort sizes of between ten days and three months, none of which has generated different results.

[Table 4 about here.]

From Table 4, it is clear that the mass point for the male parental leave distribution shifts from zero days before the reform towards 30 days after 
the reform. The fraction at zero days decreases by 36 percentage points, from 53.7 to 17.7 and the fraction in the interval between 20 and 40 days increases by 38 percentage points. Note that the reform has no effect on the distribution of 60 days or more. This makes much sense as these fathers should be unaffected by the reform.

[Figure 1 about here.]

Figure 1 plots the mean percentage of fathers on parental leave, for each month during the eight-year period we consider. The dotted line represents the control group and the solid line the treatment group. The figure reveals four differences between the treatment and the control group. First, there is some increase in male parental leave days in the first year, in particular during the summer months (holidays) and December (Christmas holidays). Second, there is a massive increase in days taken by fathers during the second year. A third effect concerns the more pronounced seasonal peaks, once more around the summer and the winter, from year three to year seven. Finally, there is a massive increase in days at the eighth year, due to the fact that parental leave must be used before the child turns eight (actually, the government informed parents about their outstanding entitlements for parental leave).

Altogether, these changes translate into two effects: fathers tend to take more time in the summer season and around Christmas, and they tend to take more time with children in the second year of their life. The seasonal pattern is reenforced in the treatment group. As compared to the control group, the amount of days taken in the summer months and in December increases by up to $100 \%$, while in other months, the increase is between $30 \%$ and $50 \%$. We have also looked at weekday effects, but have not found much of interest to go on.

\subsection{Care for sick children}

Here, we consider the second hypothesis: If more male parental leave induces some human capital acquisition for child care by males, the treatment cohort should feature a higher male share of care for sick children. First, note that the decision of parents of how to share the care for sick children is not a zero/one decision. Most children, 88 percent, are sick on at least one occasions during the period studied. Whether the father or the mother should stay at home with a sick child on a certain occasion depends on the potential problems caused at the workplace, which varies from day to day. The (dis)satisfaction from working could also vary between days. From the data, we know that most fathers have a positive share in the care for sick children: 
$23 \%$ of the sick children were only taken care of by the mother, $7 \%$ only by the father, while $70 \%$ of the mothers and fathers shared the responsibility for sick children.

We use two measures for fathers' share of care for sick children (CSC). In Table 5, MALESHARE (A) is defined as the average of the male share of care for sick children within the household; "Men's share of total number of days" (B) is simply total male days taken for care for sick children in the sample divided by total days (male and female). ${ }^{8}$ The two measures produce very similar results. For the first measure, there is no statistically significant difference in the means between the before and after reform cohorts. For the second measure, there is a small negative effect of the reform on fathers' use of parental leave for the two-week cohorts, but this effect vanishes for the three-month cohort. There are no t-statistics for the differences in this measure between the before and after group. Note, however, that these differences are very small, smaller than the insignificant differences for the variable MALESHARE.

\section{[Table 5 about here.]}

As noted above, there is a trade-off when deciding on the size of cohorts. A small sample results in a very clean natural experiment, but there are potential problems with small samples. The problems are avoided in a large sample, but would make the natural experiment less clean. For the two-week sample, for instance, there is only a 28-day difference in age between the first child in the control group and the last child in the treatment group. For the three-month sample, there is a six-month age difference between the first and the last child, making it a less clean natural experiment.

A second comment concerns the fact that children born in different years are treated differently in some respects. For example, children born in December 1994 start school one year before children born in January 1995. This could potentially lead to a "turn-of-the-year" effect in both the use of parental leave and care for sick children. To investigate turn of the year effects, we construct cohorts around the turn of the year for the six years following the reform. Table 6 shows the difference in male use of parental leave and care for sick children for each turn of the year, for both the reform year and the six following years. For the years after the reform, there seems

\footnotetext{
${ }^{8}$ The difference between the two measures is that they weight the number of CSC days differently. For instance, consider two families; the first family where the child is sick for two days, where both the father and the mother take one day of care is treated by the first measure as being the same as the second family where the child is sick for 100 days, and the mother and the father both take 50 days of care. The family with the child that is sick 100 days is weighted as 50 times as heavy by the second measure.
} 
to be no systematic difference between cohorts of children born before and after the turn of the year. Note also that only few of the changes around the turn of the year are significant, and that most of them disappear when considering the three-month cohort for both parental leave and care for sick children.

[Table 6 about here.]

Finally, we turn to the relation between fathers' use of parental leave and their share of care for sick children. The data in Table 7 show there to be a strong positive correlation between fathers' parental leave and their share of care for sick children. However, it is important to see that this correlation is not causal. First, note that in the control group, the correlation between parental leave days and the male share of care for sick children is much weaker than in the treatment group. This seems to be the result of a composition effect in the groups of fathers taking at least one day of parental leave. The proportion of fathers taking no parental leave in the control group is three times as large as in the treatment group. Most of the fathers in the treatment group take 20 to 40 days ( $46.7 \%$ of the treatment group) rather than zero days, and some take one to 20 days. Hence, it appears that there are unobserved factors that make fathers share the responsibility for care for sick children: work satisfaction, values held by fathers and mothers, long-run costs of absence from work, norms in society etc. None of them seem to be immediately affected by the exogenous increase in parental leave that is the result of the reform. The reform may have lead to a gradual change in norms in society, but with our data, it is impossible to disentangle such an effect from other changes.

\section{[Table 7 about here.]}

The design of the reform allows us to distinguish between the causal effects of parental leave on care for sick children from omitted variables. Fathers' mean share of care for sick children essentially remains unchanged. The difference between the before and after group is explained by compositional effects. This impression is further reinforced by the fact that the behavior of fathers taking more that 40 days of parental leave does not change in any significant way with the reform (note the standard deviations in parentheses).

\subsection{Further observations}

Many Swedish mass media believe that fathers in particular take parental leave when there are major sports events like the Olympic Games. We do 
not find much evidence for this, although we have experimented with different types of regression analyses. For the Winter Olympics of 1998, for instance, we find that about 0.39 percent of the fathers are on parental leave as compared to about 0.37 percent in the weeks before the event. For other major sports events, we find effects of a similar or smaller size. Statistically, it is hard to disentangle the effects of sports events from seasonal variations and the analysis is further complicated by the fact that we do not have any information about regular, paid vacation of fathers or mothers. However, as indicated by the seasonal peaks, parental leave may be used as a substitute for paid vacation. This would then free days of paid vacation for sport events. We cannot exclude such behavior, but we have no evidence for it. In any case, it seems safe to say that the economic magnitude of any possible effects of sports events on parental leave would be quite small.

\section{[Table 8 about here.]}

A second set of observations relates to the effect of fathers' and mothers' income on parental leave. Table 8 compares treatment and control groups. We infer women's income from their mean reimbursement in the 360-day system. Around $20 \%$ of the women had an income of nil or too low to receive reimbursement above the minimum amount of SEK 60 (USD 8). Hence, the two lowest deciles are pooled for women. For men, there is a potential selection problem that does not allow us to infer their income from the 360-day system. ${ }^{9}$ We measure income by the reimbursement in the ten-day system paid in connection with birth. We find fathers' parental leave to be increasing in income up to the reimbursement ceiling. This is in line with earlier research, see Sundström and Duvander (2004). The increase in fathers' parental leave is about the same for all income groups. However, while one could expect the strongest effects of the reform for subgroups where women have a higher income than men, we did not find any sign of this in the data. Rather, there seems to be a U-shaped pattern between the income of mothers and parental leave by fathers.

Fathers' parental leave is also relatively high when mothers are in the two highest income deciles, in line with the results in Sundström and Duvander (2004). We have also related the changes in care for sick children to income levels of the parents in the before and after groups. We find no systematic

\footnotetext{
${ }^{9}$ Fathers in the treatment group use the 360 -day system to a much larger extent. The ten days reimbursed in connection with the birth of a child are used by about 66 percent of the fathers, both in the treatment and the control group. The fathers who do not take any time off in connection with the child's birth are in the 1-4 cohort, so this cohort mainly consists of unobserved rather than low income.
} 
pattern for the changes between income subgroups. This is what we expected, as there is no significant difference in the mean values of care for sick children for the whole before and after group.

Another interesting observation relates to mothers in the two lowest income deciles. Here, fathers take a comparatively large number of days, and there is no increase in the treatment group. This is what to be expected from rational households. The opportunity cost for taking parental leave was very low for these fathers. Mothers only lose the low flat-rate reimbursement SEK 60 (USD 8) per day when fathers take a day of parental leave. Thus, these fathers basically face no economic restriction on the amount of parental leave they could take, neither before nor after the reform. Hence, the amount of days they take can be seen as the unconstrained maximum of parental leave by fathers. However, fathers matched with higher-income mothers face a different maximization problem, and the findings for these unconstrained fathers cannot be generalized on the entire population.

Finally, one may wonder about the fiscal implications of the reform. The introduction of the daddy-month coincided with a decrease in the reimbursement rates from 90 to $80 \%$, except for the first month that was reimbursed at $90 \%$. These new rules affected both pre- and post reform cohorts in the same way. In the sample, the reimbursement in SEK for women before the reform is almost exactly 80 percent of that for men, which is close to the difference in hourly wages for men and women in Sweden. Had the reform been implemented without the simultaneous cut in the reimbursement rate, a crude calculation gives us the following fiscal effects. First, using the threemonth-span cohorts, there is an average increase in the number of reimbursed days by fathers of 13 which, multiplied by the average reimbursement of 480 SEK, gives a cost per child of 6249 SEK. The number of reimbursed days by mothers decreased by 22.9 at an average reimbursement of 383 SEK, which gives a cost of 8770 SEK. Hence, there is a reduction in pay per child of 2128 SEK. Using the 14-day cohorts gives a similar number of 2237 SEK. Given that there are 100000 children born each year in Sweden, there is a decrease in costs for the government's budget of about 200 million SEK or 20 million Euro per year.

\section{$5 \quad$ Discussion and implications}

The main motivation for the "daddy-month reform" was to increase the opportunities of women in the labor market and induce more equal labor market outcomes. Based on Becker's work $(1965,1981,1985)$, there was a belief in society that more parental leave by fathers could help decrease the special- 
ization of mothers in human capital for household work and child care. This would, in turn, increase the household and child care human capital of fathers. The reform succeeded in inducing many fathers to take more parental leave, but it did not affect the intra-household allocation of care for sick children.

To draw conclusions from this experiment, one must ask why there were no effects on care for sick children at all. Clearly, the reform design had its weaknesses. In particular, fathers could allocate their parental leave over eight years. It should be expected that an effect on human capital and longterm behavior would be more likely, if parental leave had to be taken in a shorter period of time and when the child is very young. Probably more important is the fact that the reform may not have provided a strong enough stimulus - an average increase in fathers' parental leave by less than a month may not be sufficient to affect human capital acquisition.

Hence, it is an open question whether reforms providing stronger incentives to fathers to take parental leave could induce long-term behavioral changes. In any case, our study shows how well incentives work in the shortterm, but also how difficult it is to induce behavioral changes and household decision-making. Note that we even find very little long-run effects in the subgroups for which the effects of the reform should be most pronounced (see $4.3)$.

It is important to note that there are other economic forces than human capital acquisition that may be responsible for unequal labor market outcomes. For instance, given gender roles and norms in society, employers may interpret parental leave by fathers as a bad signal about their job commitment. Two papers have indeed found that fathers suffer greater wage losses when taking parental leave than mothers (Stafford and Sundström, 1996, Albrecht et al, 1999). This is in line with parental leave being interpreted as a signal of lacking job commitment. The daddy month has induced many fathers to use at least one month and hence, there should be less of a stigma associated with taking parental leave. However, the reform did not affect the care for sick children benefit. A theory built on signalling could thus to some extent explain the asymmetric effects concerning the two benefit systems. There are other important factors, for instance, "identity" (Akerlof and Kranton, 2000), which may explain different preferences behavior across gender.

What type of reform could teach us more about the degree to which social policies can influence household decisions concerning child care? First of all, it appears useful to carefully identify the theoretical basis for any of these reforms and generate empirical predictions. Second, one may have to experiment with more intensive reforms. Reserving half of the parental leave 
for men would indeed be such a test. However, against the background of our study, it should be clear that there are trade-offs associated with such a drastic reform. While the daddy month induced more parental leave by fathers, it should not be forgotten that it reduced total parental leave per child by five days. Consequently, a more intensive reform may have such effects on a larger scale.

In this respect, it is also important to note that at least in Sweden, the gender wage gap is very low for lower skill groups and is most significant for higher skill groups (Albrecht et al, 2003). Hence, a more drastic reform has uncertain effects in terms of labor market opportunities, but may result in welfare losses for some groups. To reduce these potential welfare losses, we hence believe that if there were such an experiment, it should not be designed for the entire economy, but rather for subgroups, for example segmented regionally. However, introducing such a reform for only part of the population may be difficult to implement.

\section{Concluding remarks}

We have investigated the effects of the daddy-month reform, introduced in Sweden in 1995. Different treatment of parents whose children were born before and after the reform provides a natural experiment. The share of fathers taking zero days of parental leave in the treatment group decreased from 54 to 18 percent, and the number of fathers using around one month of parental leave increased from 9 to 47 percent. The number of days of parental leave by fathers increased by about 15 and decreased by about 20 for mothers.

The reform reached its short-term goal of increasing fathers' parental leave remarkably well, but we have not found any signs that more parental leave has changed the behavior of fathers in terms of taking care for sick children.

Hence, it appears rather easy for a government to incentivize fathers to take parental leave. However, it appears much harder to induce behavioral changes, through the acquisition of human capital for household work and child care. 


\section{References}

Albrecht, James W., Per-Anders Edin, Marianne Sundström and Susan B. Vroman (1999), "Career Interruptions and Subsequent Earnings: A Reexamination Using Swedish Data", Journal of Human Resources, Vol 34: 294-311.

Albrecht, James W., Anders Björklund and Susan Vroman (2003), "Is There a Glass Ceiling in Sweden?", Journal of Labor Economics, Vol 21: $145-177$.

Becker, Gary S. (1965), "A Theory on the Allocation of Time", Economic Journal, Vol 77: 493-517.

Becker, Gary S. (1981), A Treatise on the Family, Harvard University Press.

Becker, Gary S. (1985), "Human Capital, Effort, and the Sexual Division of Labor" Journal of Labor Economics, Vol 3: 33-58.

Bertelsmann Foundation (2004), various issues of http://www.reformmonitor.org/

Bingley, Paul, Gauthier Lanot, Elizabeth Symons, and Ian Walker (1995), "Child Support Reform and the Labor Supply of United Kingdom Lone Mothers", Journal of Human Resources, Vol. 30:256-279.

The Economist (2004), "Forced Fatherhood", January 8th, Print Edition.

Ferrarini, Tommy (2003), Parental Leave Institutions in Eighteen Post-war Welfare States, Doctoral Dissertation, Department of Sociology, Stockholm University.

Gatenio, Shirley and Sheila Kamerman (2002), The Clearinghouse on International Developments in Child, Youth 6 Family Policies, Spring issue, http://www.childpolicyintl.org/issuebrief/issuebrief5.htm\#takeup

Gornick, Janet C. and Marcia K. Meyers (2003) Families That Work: Policies for Reconciling Parenthood and Employment, New York: Russell Sage Foundation.

Government Proposition 1993/94:147 to the Swedish Parliament.

Gregg, Paul, Elizabeth Washbrook, Carol Propper and Simon Burgess (2005), "The Effects of a Mother's Return to Work Decision on Child Development in the UK", Economic Journal, Vol. 115, 48-80. 
Gruber, Jonathan (1994), "The Incidence of Mandated Maternity Benefits", American Economic Review, Vol. 84: 622-641.

Henrekson, Magnus, (1993), "Jämställdhet ur Incitamentsperspektiv (Gender Equality: An Incentive-Based Analysis)", Ekonomisk Debatt, Vol 20 .

Kunze, Astrid and Mette Ejrnaes (2004), "Wage Dips and Drops around First Birth", IZA DP No. 1011.

Nilsson, Agneta (1994), Föräldraledighet (Parental Leave) 4th ed, Folkhälsoinstitutet (Swedish National Institute of Public Health), Stockholm.

RFV (National Social Insurance Board) (2002), Social Insurance in Figures, Stockholm.

Rosen, Sherwin, (1983), "Specialization and Human Capital", Journal of Labor Economics, Vol 1: 43-49.

Rosenzweig, Mark R. and Kenneth I. Wolpin (2000), " 'Natural' Natural Experiments in Economics", Journal of Economic Literature, Vol 38: 827-874.

Ruhm, Christopher J. (1998), "The Economic Consequences of Parental Leave Mandates: Lessons from Europe", Quarterly Journal of Economics, Vol 113: 287-317.

Ruhm, Christopher J. and Jacqueline L. Teague (1997), "Parental Leave Policies in Europe and North America", in Francine D. Blau and Ronald G. Ehrenberg (eds.) Gender and Family Issues in the Workplace, New York: Russell Sage Foundation.

Schoenberg, Uta (2005), "An Evaluation of Germany's Maternity Leave Reform", mimeo Rochester.

Stafford, Frank P. and Marianne Sundström (1996), "Time Out for Childcare: Signalling and Earnings Rebound Effects for Men and Women", Labour, 10: 609-629.

Sundström, Marianne and Ann-Zofie E. Duvander (2002), "Gender Division of Childcare and the Sharing of Parental Leave among New Parents in Sweden", European Sociological Review, Vol 18: 433-447.

Waldfogel, Jane (1998), "The Family Gap for Young Women in the United States and Britain: Can Maternity Leave Make a Difference?", Journal of Labor Economics, Vol. 16: 505-545. 
Table 1: Number of observations in different cohorts.

\begin{tabular}{lcccc}
\hline \hline Cohort & \multicolumn{2}{c}{ Two weeks* } & \multicolumn{2}{c}{ Three months** } \\
& Before & After & Before & After \\
\hline \hline Children & 3709 & 3892 & 24528 & 27619 \\
Fathers & 3134 & 3467 & 20814 & 24978 \\
Mothers & 3676 & 3866 & 24373 & 27429 \\
Both parents & 3101 & 3441 & 20659 & 24788 \\
\hline \hline
\end{tabular}

* Two-week cohorts: the before group consists of children born between December 18 and 311994.

The after group consists of children born between January 1 and 141995.

** Three-month cohorts: The before group consists of children born between October 1 and December 31 1994. The after group consists of children born between January 1 and March 311995. 
Table 2: Average age of mothers and fathers for different cohorts.

\begin{tabular}{ccccc}
\hline \hline Cohort & \multicolumn{2}{c}{ Two weeks } & \multicolumn{2}{c}{ Three months } \\
& Before & After & Before & After \\
\hline \hline Fathers & 31.98 & 31.90 & 32.05 & 31.95 \\
& $(6.03)$ & $(5.95)$ & $(5.96)$ & $(5.82)$ \\
Mothers & 29.15 & 29.06 & 29.23 & 29.16 \\
& $(5.04)$ & $(5.14)$ & $(5.14)$ & $(4.99)$ \\
\hline \hline
\end{tabular}

Note: Standard deviations in parentheses. 
Table 3: Mean of parental leave days.

\begin{tabular}{lcccccccc}
\hline \hline Cohort & \multicolumn{4}{c}{ Two weeks } & \multicolumn{5}{c}{ Three months } \\
& Before & After & Diff & T-stat & Before & After & Diff & T-stat \\
\hline \hline Fathers: & & & & & & & & \\
360-days* & 29.5 & 44.2 & 14.7 & 10.8 & 30.8 & 43.8 & 13.0 & 25.0 \\
& $(61.9)$ & $(57.4)$ & & & $\begin{array}{c}(64.1) \\
(55.1)\end{array}$ & & \\
90-days** & 8.0 & 9.3 & 1.4 & 2.8 & $\begin{array}{c}8.3 \\
8.7\end{array}$ & 0.5 & 2.6 \\
& $(21.1)$ & $(21.8)$ & & & $(21.5)$ & $(21.1)$ & & \\
Mothers: & & & & & & & & \\
360-days* & 323.7 & 298.9 & -24.7 & -12.8 & 323.8 & 300.9 & -22.9 & -32.2 \\
& $(87.3)$ & $(80.5)$ & & & $(86.5)$ & $(76.8)$ & & \\
90-days** & 59.9 & 63.1 & 3.2 & 3.2 & 59.2 & 63.6 & 4.4 & 12.1 \\
& $(42.8)$ & $(44.0)$ & & & $(42.9)$ & $(40.5)$ & & \\
\hline \hline
\end{tabular}

Notes: Standard deviations in parentheses.

* 360-days represents the parental leave system where parents are compensated for a maximum of 360 days, with a replacement rate of $80 \%$ of their estimated earnings.

* 90-days represents the parental leave system where parents are compensated for 90 days at flat rate of 60 SEK/day (appx. 8 USD). 
Table 4: Distribution of fathers' parental leave (360-days system) in percentages, for different cohorts.

\begin{tabular}{lrrrrrr}
\hline \hline Number & \multicolumn{3}{c}{ Two weeks } & \multicolumn{3}{c}{ Three months } \\
of days & Before & After & Diff & Before & After & Diff \\
\hline \hline 0 days & 53.7 & 17.7 & -36.0 & 53.2 & 16.0 & -37.2 \\
$0-10$ & 10.7 & 4.4 & -6.3 & 10.4 & 3.7 & -6.7 \\
$10-20$ & 5.6 & 5.5 & -0.1 & 5.8 & 5.4 & -0.4 \\
$20-30$ & 5.5 & 34.3 & 28.7 & 5.5 & 37.2 & 31.7 \\
$30-40$ & 3.7 & 12.4 & 8.6 & 3.8 & 12.3 & 8.5 \\
$40-50$ & 2.8 & 4.7 & 2.0 & 2.7 & 4.7 & 2 \\
$50-60$ & 2.1 & 2.9 & 0.8 & 2.2 & 3.3 & 1.1 \\
$60-70$ & 2.1 & 2.4 & 0.4 & 2.1 & 2.6 & 0.5 \\
$70-80$ & 1.5 & 1.8 & 0.2 & 1.6 & 1.9 & 0.3 \\
$80-90$ & 1.5 & 1.8 & 0.3 & 1.6 & 1.6 & 0 \\
$90-100$ & 1.1 & 1.2 & 0.1 & 1.2 & 1.4 & 0.2 \\
$100>$ & 9.6 & 10.9 & 1.3 & 9.9 & 10.0 & 0.1 \\
\hline \hline
\end{tabular}


Table 5: Fathers' share of care for sick children (CSC).

\begin{tabular}{lcccccc}
\hline \hline Cohort & \multicolumn{3}{c}{ Two weeks } & \multicolumn{3}{c}{ Three months } \\
& Before & After & Diff & Before & After & Diff \\
\hline \hline (A) MALESHARE* & 35.04 & 35.52 & 0.47 & 34.93 & 35.44 & 0.51 \\
& & & $(0.79)$ & & & $(0.30)$ \\
& & & & & & \\
$\begin{array}{l}\text { (B) Men's share of } \\
\text { total number of days** }\end{array}$ & 34.60 & 34.15 & -0.45 & 34.58 & 34.60 & 0.02 \\
N. of obs. & & & & & & \\
\hline \hline
\end{tabular}

*MALESHARE is defined as follows: Compute the male share of days spent on care for sick children by each child in the data set. MALESHARE is the average male share taken over all children (that is, across households).

**Men's share of the total number of days is: total male days divided by total days (male and female).

Note: Standard deviations in parentheses. 
Table 6: Differences around the turn of years.

\begin{tabular}{ccccccc}
\hline \hline & \multicolumn{2}{c}{ Days of men's } & \multicolumn{2}{c}{ MALESHARE } & \multicolumn{2}{c}{ Men's share } \\
& parental leave & & \multicolumn{4}{c}{ CSC percent } \\
& Two & Three & Two & Three & Two & Three \\
Cohort & weeks & months & weeks & months & weeks & months \\
\hline \hline $1994-95$ & $14.7^{* * *}$ & $13.0^{* * *}$ & 0.47 & 0.51 & -0.45 & 0.02 \\
& $(1.37)$ & $(0.52)$ & $(0.79)$ & $(0.30)$ & & \\
$1995-96$ & -1.07 & $0.98^{* *}$ & $-2.08^{* *}$ & 0.06 & -0.92 & -0.20 \\
& $(-0.80)$ & $(2.00)$ & $(0.85)$ & $(0.30)$ & & \\
$1996-97$ & 0.45 & 0.13 & 0.04 & 0.15 & -0.02 & 0.52 \\
& $(0.32)$ & $(0.27)$ & $(0.80)$ & $(0.35)$ & & \\
$1997-98$ & 0.59 & -0.48 & $1.83^{* *}$ & 0.15 & 1.77 & 0.15 \\
& $(0.45)$ & $(-0.93)$ & $(0.92)$ & $(0.35)$ & & \\
$1998-99$ & $2.29^{*}$ & 0.55 & 0.41 & 0.22 & -0.87 & 0.44 \\
& $(1.67)$ & $(1.06)$ & $(0.98)$ & $(0.36)$ & & \\
$1999-00$ & $-3.02^{* *}$ & 0.47 & -0.47 & -0.15 & -2.15 & -0.34 \\
& $(-2.12)$ & $(-0.92)$ & $(1.07)$ & $(0.39)$ & & \\
$2000-01$ & -0.49 & 0.33 & $2.21^{* *}$ & -0.28 & -0.22 & -0.64 \\
& $(-0.36)$ & $(0.65)$ & $(1.12)$ & $(0.52)$ & & \\
\hline \hline
\end{tabular}

Notes: Differences stared with ${ }^{*}$ are significant at the ten-percent level, with ** at the five- percent level and $* * *$ at the one-percent level.

Standard errors in parentheses. 
Table 7: Fathers' share of care for sick children measured by MALESHARE grouped by parental leave days (PLdays).

\begin{tabular}{lcccc}
\hline \hline Cohort & \multicolumn{4}{c}{ Two weeks } \\
Number of & \multicolumn{2}{c}{ Before } & \multicolumn{2}{c}{ After } \\
PL-days & CSC & Freq. & CSC & Freq. \\
\hline \hline PL-days $=0$ & 29.0 & 53.7 & 16.8 & 17.7 \\
& $(0.8)$ & & $(1.4)$ & \\
$0<$ PL-days $\leq 20$ & 35.6 & 16.3 & 34.4 & 9.9 \\
& $(1.3)$ & & $(1.7)$ & \\
$20<$ PL-days $\leq 40$ & 37.4 & 9.2 & 35.4 & 46.7 \\
& $(1.7)$ & & $(0.8)$ & \\
$40<$ PL-days $\leq 60$ & 42.1 & 4.9 & 41.8 & 7.6 \\
& $(2.4)$ & & $(1.9)$ & \\
PL-days $>60$ & 49.4 & 15.8 & 47.7 & 18.1 \\
& $(1.4)$ & & $(1.2)$ & \\
\hline \hline
\end{tabular}

Note: Standard deviation in parentheses. 


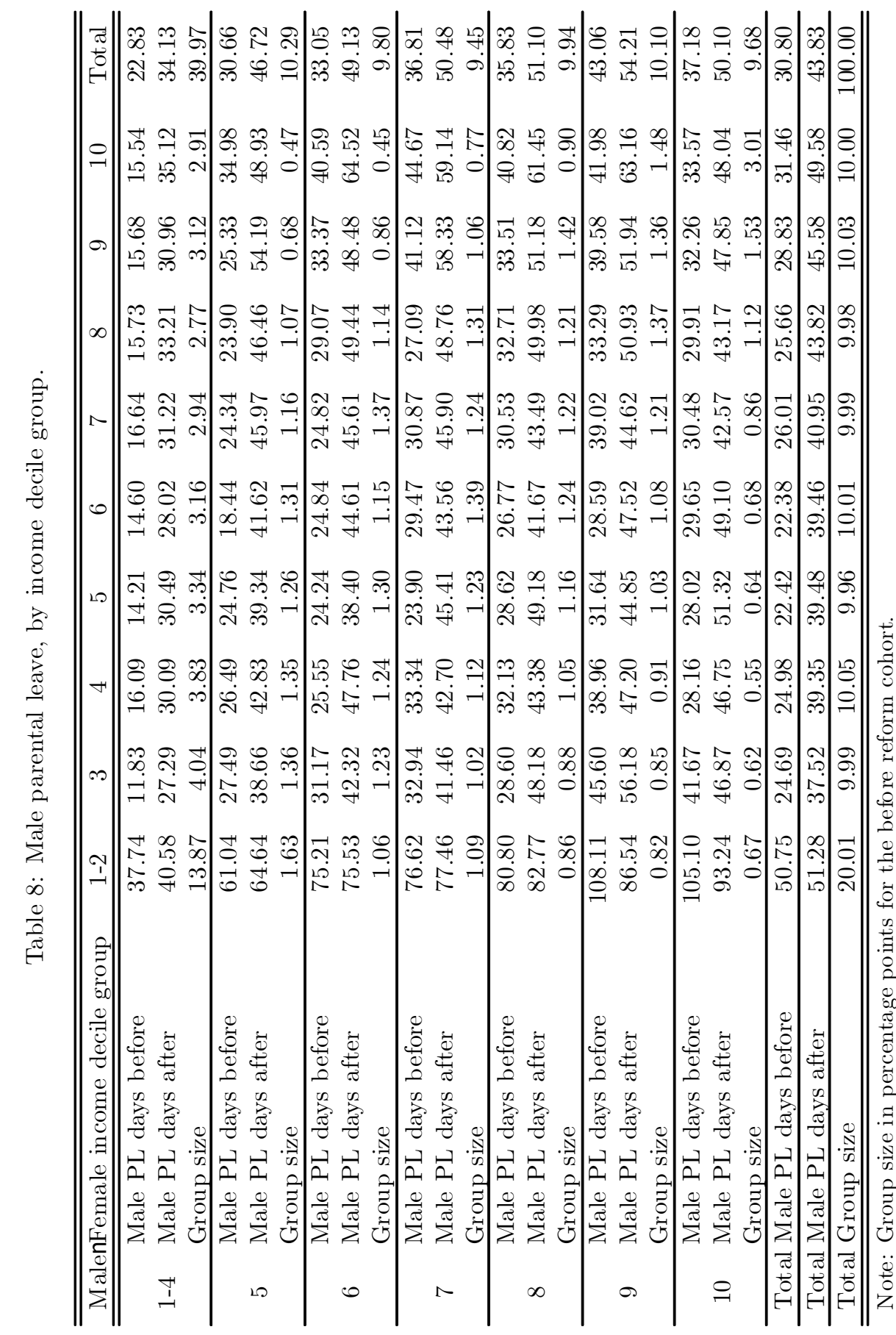




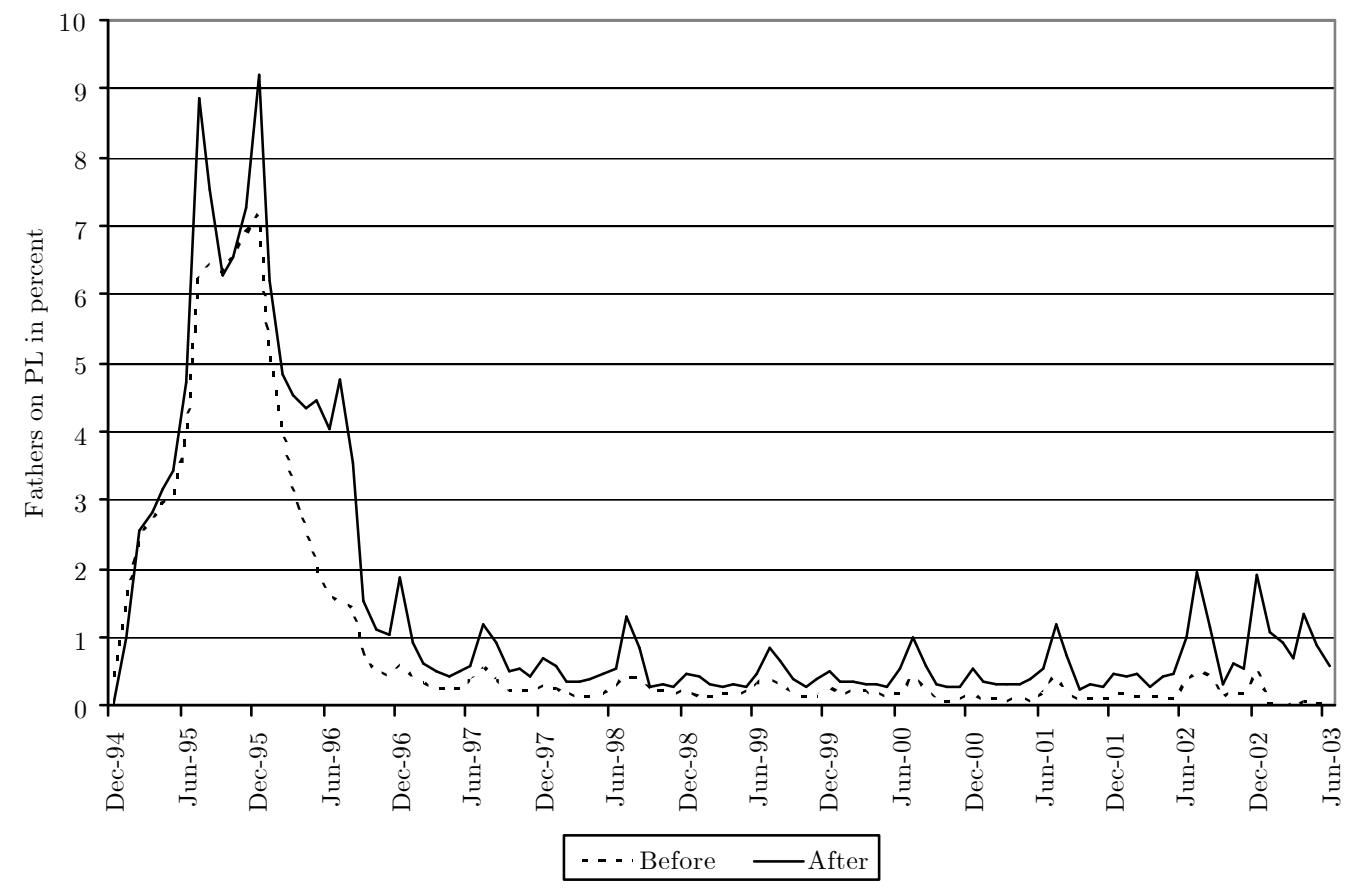

Figure 1. Mean percentage of fathers on parental leave in a given month. 